УДК 622.06

\title{
АНАЛИЗ ТЕХНОЛОГИЧЕСКИХ СХЕМ ДОБЫЧИ ЗАПАСОВ УГЛЯ НА УГОЛЬНЫХ ПРЕДПРИЯТИЯХ ЮГА КУЗБАССА, В ЗАВИСИМОСТИ ОТ ПРИМЕНЯЕМЫХ СХЕМ БОРЬБЫ С ДИНАМИЧЕСКИМИ ЯВЛЕНИЯМИ
}

\begin{abstract}
Варгольских Анастасия Анатольевна аспирант, инженер по горным работам АО «Распадская-Коксовая» Научный руководитель: Клишин Владимир Иванович д.т.н., проф. чл.-корр. РАН Директор Института угля ФИЦ УУХ СО РАН
\end{abstract}

Аннотация: в статье представлены объемы добычи на различных шахтах Томь-Усинского и Ерунаковского месторождения, произведен расчет коэффициента вариации, изучен опыт отработки мощных пластов, рассмотреныметодики расчета ширины межлавных и охранных целиков.

Ключевые слова: коэффициент вариации, слоевая отработка мощных пластов, технология выпуска угля при отработке мощных угольных пластов, расчет параметров угольных охранных и межлавных целиков.

\section{ANALYSIS OF TECHNOLOGICAL SCHEMES FOR THE EXTRACTION OF COAL RESERVES AT COAL ENTERPRISES IN THE SOUTH OF KUZBASS, DEPENDING ON THE APPLIED SCHEMES FOR COMBATING DYNAMIC PHENOMENA}

\section{Vargolskikh Anastasia Anatolyevna Scientific adviser: Klishin Vladimir Ivanovich}

\begin{abstract}
: the article presents the production volumes at various mines of the Tom-Usinsky and Yerunakovsky reservoirs, the coefficient of variation is calculated, the experience of working out powerful layers is studied, the methods of calculating the width of the inter-head and guard pillars are considered.

Key words: coefficient of variation, layer mining of heavy layers, technology of coal production during the development of powerful coal seams, calculation of parameters of coal security and inter-main pillars.
\end{abstract}


По запасам каменного угля Российская Федерация занимает второе место в мире. В России сконцентрировано по различным данным от 17,6 до $18,2 \%$ этогополезного ископаемого. В абсолютных показателях это составляет более 157 млрд. т (107,9 млрд. т бурого и 49,1 млрд. т. каменного угля) [1].

Запасы каменного угля сосредоточены в 22 бассейнах и 129 отдельных месторождениях, но не все они имеют промышленное значение. Большая часть предприятий по добыче угля, сконцентрирована в Сибири и на Дальнем Востоке [1]. Значительная часть месторождений углей в Кузбассе многопластовые. Средняя мощность угольных пластов в бассейне равна 4 м. Имеются значительные запасы углей - 31,8 млрд. т., добыча которых может осуществляться открытым способом. Основная масса этих углей - 19,4 млрд.т. или $60,9 \%$ сосредоточенная в пластах мощностью от 3,51 до 15 м; 11,9 млрд.т. (37,5\%) сконцентрирована в пластах от 1,21 до 3,5 м и 496 млн. т в пластах мощностью свыше 15 м [2].

На рисунке 1 представлены данные объемов добычи по шахтам ТомьУсинского и Ерунаковского месторождения.

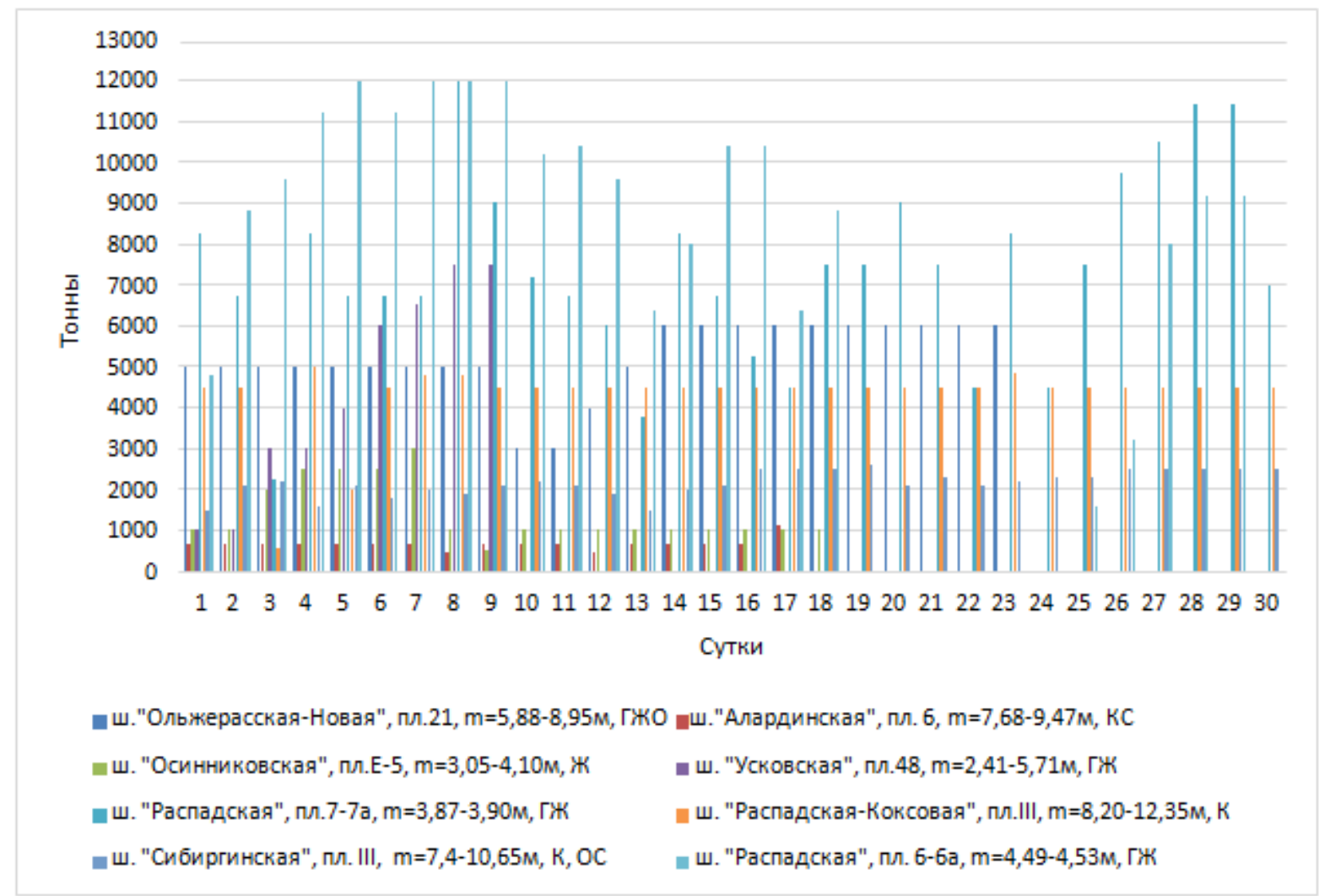

Рис. 1. Суточная добыча из очистных забоев по пластам m>3,5 м 
По полученным данным проведен расчет коэффициента вариации. Коэффициент вариации определяется по формуле [3]:

$$
V=\frac{s}{x} 100 \%
$$

где s - среднее квадратическое отклонение, т/сут;

$\bar{x}$

$x$ - среднее значение исследуемого показателя, т/сут.

На шахтах, ведущих отработку пластов $\mathrm{m}>3,5$ м, коэффициент вариации по расчетным данным составит от 53,19 до $58,86 \%$ на шахтах «Осинниковская» $\left(\mathrm{m}_{\mathrm{cp}}=3,58 \mathrm{~m}\right)$, «Усковская» $\left(\mathrm{m}_{\mathrm{cp}}=4,06 \mathrm{м}\right)$ составляет более $33 \%$, что указывает на неоднородность данных по объемам добычи. Это объясняется тем, что в разные дни добывается большее количество тонн по сравнению с другими, это связано с благоприятными горно-геологическими и техническими возможностями применяемой техники. Малые значения по объемам добычи свидетельствуют о негативном влиянии природных и горнотехнических факторов. Однородные данные, то есть каждые сутки получают примерно один и тот же объем добычи, нет слишком больших или малых значений, которые составляют менее $33 \%$ коэффициента вариации, получены по следующим шахтам «Ольжерасская - Новая» $\left(\mathrm{m}_{\mathrm{cp}}=7,42\right.$ м), «Распадская» $\left(\mathrm{m}_{\mathrm{cp}}=3,89 \mathrm{~m}\right)$, «Сибиргинская» $\left(\mathrm{m}_{\mathrm{cp}}=9,03 \mathrm{~m}\right)$, «Алардинская» $\left(\mathrm{m}_{\mathrm{cp}}=8,58 \mathrm{~m}\right)$, «Распадская-Коксовая» $\left(\mathrm{m}_{\mathrm{cp}}=10,28 \mathrm{~m}\right)$.

Проанализировав данные рисунка 1, можно сделать вывод, что максимальная добыча на пластах более 3,5 м составляет 12000 т/сут, средние значения соответственно равны 6150 т/сут.

В настоящий период угольные компании оснащены высокопроизводительной горной техникой, для безопасной и эффективной работы которой необходимо создавать условия, позволяющие достигать значительных нагрузок на добычные забои. Данный факт предопределяет потребность сокращения комплекса локальных мер прогноза и предупреждениядинамических явлений, применяемых при работе очистных и проходческих забоев, в пользу более широкого применения комплекса региональных мероприятий. Например, приведение горного массива в безопасное состояние с применением региональных (дистанционных) способов, при постоянном мониторинге НДС (напряженно-деформированного состояния) массива многофункциональной системой безопасности (МФСБ), с дальнейшей интерпретацией полученных результатов разгружающего 
воздействия на массив и выдачей разрешения на возобновление горных работ соответствующей организацией [4].

Неожиданные неуправляемые динамические обрушения горного массива наносят большой вред: опасны для людей, разрушают механизмы и горные выработки. Кроме того, зависание кровли вызывает концентрацию горного давления на угольный массив в зоне очистного забоя и на сопряжениях его с горными выработками, что провоцирует горный удар. Это приводит к разрушению горных выработок и соответственно к нарушению нормального режима работы добычных участков и к нарушению режимов проветривания забоев.

Анализируя данные по авариям за последние 20 лет, которые произошли в подземных горных выработках шахт «Юбилейная» (2007 г), «им. В.И. Ленина» (2008 г), «Распадская» (2010 г), использующих самую высокопроизводительную современную технику, обеспечивающую безопасность и комфортность всех технологических операций, можно сделать вывод о том, что на данных предприятиях не уделено внимание прогнозированию и своевременной разработке мероприятий по недопущению, динамических явлений.

Одной из основных причин взрыва метана на шахтах «Тайжина» (2004 г) и «Ульяновская» (2007 г) стало обрушение кровли на значительной площади при отходе лавы, что привело к образованию избыточного вентиляционного давления, выделению метана и угольной пыли в действующие горные выработки [5,6].

Сложность отработки мощных пологих угольных пластов с разделением нанаклонные, горизонтальные либо поперечно-наклонные слои и склонных к эндогенным пожарам заключается в оставлении межлавных и охранных целиков, оконтуривающих выемочную единицу. Также известен способ отработки мощных угольных пластов с выпуском угля, который подразумевает отработку мощного пласта на полную мощность. В связи с рассмотренными технологиями есть необходимость рассмотрения расчетов по охранным и межлавным целикам [7].

В соответствии с Руководством по безопасности «Рекомендации по безопасности ведения горных работ...» [8] ширина рассматриваемых охранных целиков определяется по ширине зоны опорного давления, определяемой согласно «Инструкции по прогнозу динамических явлений...» [9], а также «Методическому руководству...» [10]. 
Окончательно ширина охранных целиков принимается по наибольшему значению, полученному при расчетах по данным методикам.

Согласно «Рекомендациям по безопасности ведения горных работ...» [8] ширина целика между двумя параллельными выработками, пройденными по пласту, принимается из условия:

$$
l_{\text {oxp }} \succ 0,5 l
$$

где $l$ - ширина зоны опорного давления, определяемая по номограмме [8].

На мощных пластах, отрабатываемых слоями, при отработке первого слоя lопределяется с учетом вынимаемого слоя $m_{\text {вын.сл }}$. При выемке второго и следующих слоев ширина целика принимается равной:

$$
l_{\text {охр }} \geq l+\sum_{i=1}^{n} 1.5_{\text {езн.сл.і }}
$$

В основу методики расчета охранных целиков по их несущей способности положен принцип, заключающийся в том, что действующая на него нагрузка, взятая с некоторым запасом, должна уравновешиваться его несущей способностью [11], т.е.

$$
P_{\phi} \cdot n_{u}=P_{н}
$$

Ширина межлавных целиков в контурах лав рассчитывается в соответствии с Руководством по безопасности «Рекомендации по безопасности ведения горных работ ...»[8], определяется по ширине зоны опорного давления, определяемой согласно «Инструкции по прогнозу динамических явлений...» [9], а также, «Правилам охраны...» [11] и «Указаниям...» [13]. Окончательно ширина целиков принимается по наибольшему значению, полученному при расчетах по данным методикам.

\section{Выводы:}

- как показывает коэффициент вариации, на объемы добычи влияют геологические и горнотехнические факторы. При благоприятном стечении обстоятельств возможны максимальные показатели по объемам добычи за сутки, также прослеживается стабильные объемы характерные именно данной геологической мощности пласта;

- рассмотрены варианты отработки мощных угольных пластов. В каждом варианте есть свои достоинства и недостатки. При отработке слоями есть необходимость оставлять защитную межслоевую пачку угля в 
выработанном пространстве. Также применяется специфическая конфигурация межлавных целиков в форме пирамиды. При отработке мощного пласта с выпуском подкровельной толщи необходимо рассматривать целики с большей шириной и соответственно с большей несущей способностью. Так как эти параметры зависят от вынимаемой мощности и глубины ведения работ;

- рассмотрены методики и рекомендации по расчетам межлавных и охранных целиков при отработке мощных пластов. По полученным данным необходимо принимать наибольшее значение для обеспечения безопасной работы добычных забоев.

\section{Список литературы}

1. Добыча угля в России [Электронный ресурс] - URL.: https://gruntovozov.ru/chasto-zadavayemiye-voprosy/dobyicha-kamennogouglya/dobyicha-uglya-v-rossii/, свободный (дата обращения 25.12.2020)

2. Большой архив документов. Большинство месторождений углей в Кузбассе многопластовые [Электронный ресурс] - URL.:https://odnopartiec.ru/ 5464 , свободный ресурс (дата обращения 25.12.2020)

3. В.Г. Минашкин, Р.А. Шмойлова, Н.А. Садовникова, Л.Г. Моисейкина, Е.С. Рыбакова. Теория статистики [Текст]: Учебнометодический комплекс. - М.: Изд. центр ЕАОИ. 2008. - 296 с.

4. Вернигор В.М. Технология управления состоянием горного массива // Neftegaz.RU, 2019, №10, [Электронный pecypc] - URL.: https://magazine.neftegaz.ru/articles/prombezopasnost/499933-tekhnologiyaupravleniya-sostoyaniem-gornogo-massiva/, свободный ресурс (дата обращения 26.12.2020)

5. Оганесян С.А. Авария в Филиале «Шахта Тайжина» ОАО ОУК «Южкузбассуголь» - хроника, причины, выводы // Уголь, 2004, № 6, с.25-28.

6. Клишин В.И., Опрук Г.Ю., Черепов А.А. Комплексный метод снижения удароопасности на угольных шахтах // Уголь, 2018, №9, с 56-61.

7. Клишин В.И. Обоснование технологий разработки мощных пологих и крутых угольных пластов с выпуском угля // Горный информационноаналитический бюллетень (научно-технический журнал), 2014, №6, с 36-47.

8. Федеральная служба по экологическому, технологическому и атомному надзору. Приказ от 21.08.2017 №327. Об утверждении руководства по безопасности «Рекомендации по безопасному ведению горных работ на склонных к динамическим явлениям угольных пластах», 2017. 
9. Инструкция по прогнозу динамических явлений и мониторингу массива горных пород при отработке угольных месторождений, 2017.

10. Методическое руководство по выбору геомеханических параметров разработки угольных пластов короткими забоями. С-Петербург - 2003г.

11. ПБ 07-269-98. Правила охраны сооружений и природных объектов от вредного влияния подземных горных выработок на угольных месторождениях. С-Пб.: ВНИМИ, 1998, -291 с.

12. Правила охраны недр. М. - 2003, - 27c.

13. Указания по рациональному расположению, охране т поддержанию горных выработок на угольных шахтах СССР. Л.: ВНИМИ, 1986, 222 с.

(С) Варгольских А.А, 2021 